\title{
Allometric relationships for biomass and leaf area of beech (Fagus sylvatica L)
}

\author{
HH Bartelink \\ Wageningen Agricultural University, Department of Forestry, \\ PO Box 342, 6700 AH Wageningen, the Netherlands
}

(Received 13 September 1995; accepted 26 February 1996)

\begin{abstract}
Summary - The objectives of this study were i) to establish allometric relationships among stem and crown dimensions, biomass, and leaf area, ii) to determine the relative aboveground biomass distribution, iii) to quantify the relationship between leaf area and the water-conducting cross-sectional stem area, iv) to determine the vertical gradient of the specific leaf area (SLA) and v) to estimate aboveground stand biomass and leaf area index (LAI). Thirty-eight trees were sampled, ranging in age from 8-59 years. Tree biomass amounts increased with increasing diameter at breast height (dbh). Nonlinear models on dbh explained more than $90 \%$ of the biomass variance; regressions improved when tree height was used as well. Crown dimensions increased with stem size. A linear relationship was found between basal area and crown length. Crown projection area was nonlinearly related to leaf area and crown biomass. The fraction of dry matter present in the stem generally increased with tree biomass, but differently for trees from different diameter classes. The ratio between leaf and branch biomass decreased significantly with increasing tree size. The ratio between leaf biomass and leaf area (SLA) was relatively constant for whole trees, amounting on average to $172 \mathrm{~cm}^{2} \mathrm{~g}^{-1}$. SLA generally increased from the tree top down to the crown base; this pattern did not significantly differ among trees within a stand. The rate of change decreased with decreasing canopy closure. A strong linear relationship existed between leaf area and sapwood area: the ratio was affected by the height of the crown base. Aboveground stand biomass ranged from 6 to 167 ton ha ${ }^{-1}$, and increased linearly with stand age. LAI reached a maximum of seven; the leveling off was ascribed to self-thinning.
\end{abstract}

\section{Fagus sylvatica / allometry / sapwood / biomass / self-thinning}

Résumé - Relations allométriques entre la biomasse et la surface foliaire du hêtre (Fagus sylvatica $L$ ). Les objectifs de l'étude étaient i) l'établissement de relations allométriques entre la dimension du tronc, la dimension de la couronne, la biomasse, et la surface foliaire, ii) le calcul de la distribution de la biomasse aérienne entre différents organes, iii) la quantification des relations entre la surface foliaire et la section du tronc, iv) l'établissement du gradient vertical de la surface foliaire spécifique (SLA), et v) l'estimation du biomasse aérienne et de l'indice foliaire (LAI). Au total, 38 individus ont été échantillonnés, dont l'âge variait entre 8 et 59 ans. En général, la biomasse augmente avec le diamètre du tronc à $1,30 \mathrm{~m}$. Des modèles non-linéaires du diamètre expliquent plus de $90 \%$ de la variation de la biomasse. Les régressions étaient améliorées dans les cas où le diamètre et la hauteur étaient tout deux inclus. La dimension de la couronne augmente avec le diamètre du tronc.

Tel: (31) 317482 849; fax: (31) 317483 542; e-mail: hank.bartelink@btbo.bosb.wau.nl 
La surface et la hauteur de la couronne augmentent avec le diamètre du tronc. La surface de la projection de la couronne est liée de façon non-linéaire avec la surface foliaire et la masse de la couronne. Les proportions des matériaux secs des branches augmente avec la biomasse. La proportion entre la biomasse des feuilles et la biomasse des branches diminue avec l'augmentation de la hauteur de l'arbre. La relation entre la biomasse des feuilles et la SLA est constante et a une moyenne de $172 \mathrm{~cm}^{2} \mathrm{~g}^{-1}$. SLA croît du sommet de la couronne vers la base de la couronne. Cette relation ne changeait pas entre les arbres dans la parcelle étudiée. La vitesse de variation de SLA diminue dans des conditions plus ouvertes. La relation linéaire entre la surface des feuilles et la surface d'aubier est influencée par la hauteur de la base de la couronne. La biomasse aérienne varie entre $6 \mathrm{et}$ $167 \mathrm{tha}^{-1}$, et crô̂t de façon linéaire avec l'âge de la parcelle. LAI était entre 3 et 7 : maximum LAI était liée avec mortalité naturelle.

\section{Fagus sylvatica / allometry / aubier / biomasse / mortalité naturelle}

\section{INTRODUCTION}

Allometric relationships among tree dimensions, biomass amounts and foliage area form useful tools when developing mechanistic models of forest growth (see Jarvis and Leverenz, 1983; Causton, 1985). Leaf area is generally considered to play a key role as it is the main variable controlling radiation interception. The amount of leaf area is functionally related to the water-conducting sapwood area (Shinozaki et al, 1964; Jarvis and Leverenz, 1983), and to the branch biomass, which mechanically supports the foliage.

The stem provides the physiological and physical support of the crown. Sapwood area is related to the amount of water-transpiring foliage (Jarvis and Leverenz, 1983), stem diameter indicates the amount of biomass that is supported (Causton, 1985), whereas the relationship between stem diameter and tree height and/or crown dimensions will be determined by the need for mechanical stability (Niklas, 1992). Stem dimensions therefore form important indicators of crown size.

Not enough data are available yet to build reliable mechanistic models (Cannell, 1989). The present study therefore focused on tree dimensions, biomass and leaf area interrelationships of beech (Fagus sylvatica $\mathbf{L}$ ), as part of the development of a mechanistic model of forest growth. The aims of the study were: i) to establish allometric relationships among stem and crown dimensions, biomass amounts, and leaf area, ii) to determine the aboveground dry matter distribution, iii) to quantify the relationship between sapwood area and leaf area, iv) to de- termine the vertical gradient of the specific leaf area (SLA) within the crown and v) to estimate aboveground stand biomass and leaf area index (LAI). The results of this study will be used to simulate growth and yield of forest stands.

\section{METHODS}

\section{Data collection}

Thirty-eight trees were selected from six evenaged beech stands, located in a forest area in the centre of the Netherlands. To obtain a range of tree sizes, stands of different ages were chosen. All stands were growing on acid brown podsolic soils in ice-pushed preglacial deposits with deep groundwater tables ( $>5 \mathrm{~m}$ below surface). Stand characteristics were derived from measuring the diameter at breast height (dbh) of all trees in a certain sample area, and from the heights of the selected trees (table I). The sizes of the sample areas varied between 250 and $1000 \mathrm{~m}^{2}$, including at least 36 trees: the largest sample consisted of 81 trees. Within the sample areas the trees were divided into two diameter classes ('small trees' versus 'large trees') of equal tree number: from each class one to three sample trees were chosen which had dbhs equal or close to the average dbh of that class. According to the criteria of Kraft (1884), all small trees could be classified as suppressed individuals, whereas the large trees were classified as (co-)dominants.

Sampling took place in the second half of July and the first half of August, in 1990, 1992 and 1993 (table I). Before felling, vertical crown projection area was determined. Horizontal 
Table I. Characteristics of the sample stands.

\begin{tabular}{|c|c|c|c|c|c|c|c|}
\hline Stand & $\begin{array}{c}\text { Cutting age } \\
\text { (years) }\end{array}$ & $N$ & $\begin{array}{c}G \\
\left(m^{2} \cdot h a^{-I}\right)\end{array}$ & $\begin{array}{l}\text { Hdom } \\
(\mathrm{m})\end{array}$ & $\begin{array}{c}d \\
(\mathrm{~cm})\end{array}$ & $H y$ & $N s$ \\
\hline 1 & 8 & 7200 & 5.54 & 3.5 & 3.13 & $1990^{*}$ & 3 \\
\hline 2 & 11 & 9920 & $2.88^{\mathrm{a}}$ & 4.2 & 3.17 & $1993^{*}$ & 6 \\
\hline 3 & 20 & 5200 & $31.42^{b}$ & 10.2 & 7.81 & $1990^{*}$ & 4 \\
\hline 4 & $21 / 22$ & 2920 & 19.69 & 9.5 & 9.27 & $1992 * / 1993$ & 10 \\
\hline 5 & $38 / 40 / 41$ & 810 & 26.21 & 17.8 & 20.30 & $1990 / 1992 * / 1993$ & 11 \\
\hline 6 & $58 / 59$ & 360 & 21.97 & 22.5 & 27.87 & $1992 * / 1993$ & 4 \\
\hline
\end{tabular}

$\mathrm{N}$ : number of trees per hectare; G: basal area; Hdom: average height of the three highest sample trees; d: average diameter of the beeches (square root of average tree basal area); Hy: year of harvest; Ns: number of sample trees. ${ }^{a}$ With $17 \%$ of $\mathrm{G}$ and $69 \%$ of $\mathrm{N}$ being Douglas-fir and birch; ${ }^{b}$ with $33 \%$ of $\mathrm{G}$ and $15 \%$ of $\mathrm{N}$ being oak; *year of stand inventory.

crown extension was estimated visually from the ground in eight different azimuthal directions: crown projection area was estimated from the average crown radius. After felling, tree length was measured. From a subsample of 20 trees, height of the crown base (height of the lowest living foliage, excluding epicormics) was measured as well. Random leaf samples were collected from each crown to determine average SLA $\left(\mathrm{cm}^{2}\right.$ fresh area/gram dry weight). The crowns of the 1993 sample trees were divided into ten horizontal layers of approximately uniform depth, and at each boundary a subsample of 20-25 leaves was taken to determine height-related SLA differences. Next, all living branches and leaves were collected: for each tree the leaf-bearing branches were cut into smaller pieces (with a maximum length of 1.5 $\mathrm{m}$ ) and put into plastic bags, whereas the leafless branch parts were sawn into 4 m pieces. All biomass samples were taken to the laboratory. Stem volume followed from stem diameter measurements at regular distances along the stem. From each tree a stem disk was removed at breast height and taken to the laboratory.

In the laboratory, projected leaf areas of the fresh leaf samples were determined using the Delta-T Image analyses system. The leaf-bearing branches were dried for 2 days at $22-25^{\circ} \mathrm{C}$ in a drying chamber (relative air humidity decreased to approximately $30 \%$ ), to simplify the separation of foliage and woody parts. After the leaves had been removed physically, samples were oven-dried to determine dry weights of the leaf $\left(24 \mathrm{~h} ; 70^{\circ} \mathrm{C}\right)$ and of the defoliated branches $\left(48 \mathrm{~h} ; 105^{\circ} \mathrm{C}\right.$ ), and to estimate total dry weights. The leafless branch parts were chipped and weighed; dry weight was determined based on the ratio between fresh weight and oven-dry weight of a sample of chipped branch parts. Total branch dry weight followed from summing the dry weights of the defoliated branches and the leafless branch parts. Stem dry weight was determined by multiplying stem volume with a wood basic density of $550 \mathrm{~kg}$ dry weight per $\mathrm{m}^{3}$ fresh volume (Burger, 1950).

As the boundary between sapwood and heartwood can be difficult to recognize in beech (Zimmermann, 1983; Hillis, 1987), the visual check was accompanied with the application of several chemical solutions which work on differences in chemical composition between sapwood and heartwood (Bamber and Fukazawa, 1985; Hillis, 1987): we applied ferric chloride, floroglucinol, fuchsine, safranine and fastgreen, respectively. The cross-sectional area of each sapwood ring was determined using a digital stem disk analysis system.

\section{Data analysis}

Relationships between stem and crown dimensions, biomass amounts and leaf area were analyzed. Crown silhouette area (horizontal projection) was derived from crown length and vertical projection area, assuming that the 
crown can be described by an ellipsoid. Apart from the total sapwood area at breast height $\left(s a_{b h}\right)$, also the cumulative area of the most recent growth rings was determined. The area of only the most recent rings might be closer related to total leaf area because, in general, the contribution of a growth ring to the vertical water transport declines with ring aging (Zimmermann, 1983). In order to be able to include data from younger trees as well, only up to six growth rings were taken into account.

Biomass distribution was described as a function of total aboveground biomass. In this approach, first the ratios of foliage to stem dry weight and branch to stem dry weight are calculated and related to the total biomass, after a two-sided logarithmic transformation. The following relationships were analyzed:

$$
\begin{aligned}
& \ln \left(\mathrm{w}_{l} / \mathrm{w}_{s}\right)=\mathrm{c}_{1}+\mathrm{c}_{2} * \ln \left(\mathrm{w}_{t}\right) \\
& \ln \left(\mathrm{w}_{b} / \mathrm{w}_{s}\right)=\mathrm{c}_{3}+\mathrm{c}_{4} * \ln \left(\mathrm{w}_{t}\right)
\end{aligned}
$$

were $\mathrm{w}_{l}=$ tree leaf biomass $(\mathrm{kg}) ; \mathrm{w}_{b}=$ tree branch biomass $(\mathrm{kg}) ; \mathrm{w}_{s}=$ tree stem biomass $(\mathrm{kg}) ; \mathrm{w}_{t}=$ total tree biomass $(\mathrm{kg}) ; \mathrm{c}_{1}-\mathrm{c}_{4}=$ regres-sion constants.

From these equations, the mathematical descriptions of, respectively, $\mathrm{w}_{l} / \mathrm{w}_{t}, \mathrm{w}_{b} / \mathrm{w}_{t}$ and $\mathrm{w}_{s} / \mathrm{w}_{t}$ were solved as functions of $\mathrm{w}_{t}$.

Regression analyses were carried out using the GENSTAT statistical package. All regression estimates presented were significant (at least) at the $5 \%$ level. The fraction of variance accounted for $\left(R^{2}\right)$ has been adjusted for the number of degrees of freedom.

Both linear and nonlinear models were tested. In the case of linear regression analysis the model was fitted by linear least squares. Linear regression analysis is commonly used in biomass research after carrying out a so-called two-sided log transformation: a log transformation (natural logarithm) of both the dependent and the independent variables (Causton, 1985). In the case of nonlinear regression analysis the model was fitted directly by nonlinear least squares. The presentation of the fitted models is in accordance with the statistical approach applied. In the case of linear regression after a $\log -\log$ transformation, the power model deri-

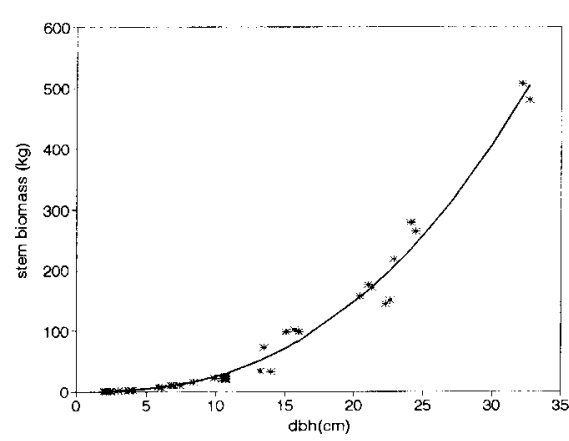

a

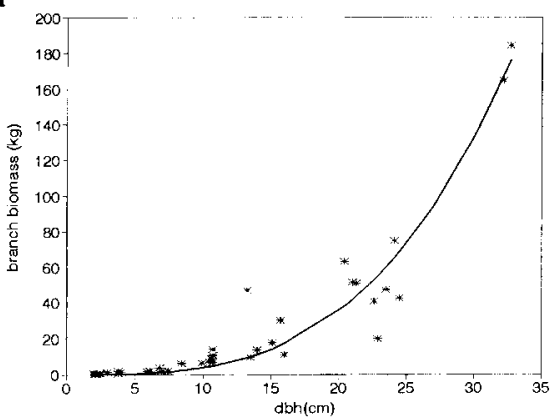

b

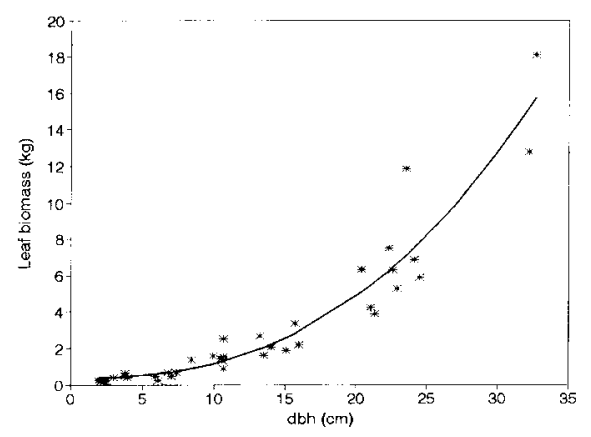

c

Fig 1. Stem (a), branch (b) and leaf (c) biomass, related to diameter at breast height (dbh). Data are represented by asterisks, the regression equations by the solid line. Parameter estimates of the regression equations can be found in table II. 
Table II. Nonlinear models between tree biomass amounts or leaf area ( $\mathrm{Y}$ : in $\mathrm{kg} \mathrm{or} \mathrm{m}^{2}$ ) and $\mathrm{dbh}$ (in $\mathrm{cm}$ ).

\begin{tabular}{lcccccc}
\hline \multicolumn{1}{c}{$Y$} & $c_{\theta}$ & $c l$ & $S E c l$ & $c_{2}$ & $S E c_{2}$ & $\mathrm{R}^{2}$ \\
\hline Leaves & 0.375 & 0.0024 & 0.0021 & 2.517 & 0.253 & 0.906 \\
Branches & $*$ & 0.0020 & 0.0016 & 3.265 & 0.236 & 0.916 \\
Crown & $*$ & 0.0031 & 0.0023 & 3.161 & 0.216 & 0.924 \\
Stem & $*$ & 0.0762 & 0.0224 & 2.523 & 0.088 & 0.979 \\
Total & $*$ & 0.0798 & 0.0191 & 2.601 & 0.072 & 0.988 \\
Leaf area & 8.560 & 0.0286 & 0.0213 & 2.623 & 0.218 & 0.932 \\
\hline
\end{tabular}

The models are of the form $\mathrm{Y}=\mathrm{c}_{0}+\mathrm{c}_{1} * \mathrm{dbh}^{22}$. Standard errors (SE) of the estimates are indicated. The number of observations is 38 . ${ }^{*}$ Intercept not significant.

ved from the log model is presented as well to facilitate comparison with other models.

\section{RESULTS}

\section{Allometric relationships}

Stem biomass, branch biomass, leaf biomass, crown biomass (branches and leaves) and leaf area were nonlinearly related to dbh (fig 1), which, in all cases, explained over $90 \%$ of the variance (table II). The relationships did not differ between trees from different size classes or stands. Adding tree height as a predicting parameter resulted in a slight increase of the regression coefficients $R^{2}$ (table III). Leaf area and leaf biomass were strongly linearly interrelated $\left(R^{2}=0.987\right)$; the average ratio (SLA) amounted to $172 \mathrm{~cm}^{2} \mathrm{~g}^{-1}$.

Stem and crown dimensions generally increased with increasing dbh, but large variability occurred. The relationship between $\mathrm{dbh}$ and tree height was best described after a $\log$-log transformation of both variables:

$$
\ln (\mathrm{h})=0.549+0.769^{*} \ln (\mathrm{dbh}) \quad R^{2}=0.934[\mathrm{la}]
$$

Transformed to a power function it reads as follows:

$$
h=1.732 * \mathrm{dbh}^{0.769}
$$

where $\mathrm{h}=$ tree height $(\mathrm{m})$ and $\mathrm{dbh}=$ stem diameter at breast height $(\mathrm{cm})$.

Crown base height (subsample of 20 trees from four different stands) was rather constant within a stand, but differed significantly between the stands. Crown length appeared to be strongly correlated with stem basal area.

$$
\mathrm{c}_{l}=2.897+1.432 * \text { ba } R^{2}=0.888
$$

where $\mathrm{c}_{l}=$ crown length $(\mathrm{m})$ and $\mathrm{ba}=$ stem basal area at breast height $\left(\mathrm{dm}^{2}\right)$.

Crown silhouette area and tree height were clearly correlated with dbh. Following Niklas (1992), the product of silhouette area and tree height was related to dbh, after a two-sided log transformation (see eq [3a]). Exchanging the dependent and independent variables revealed

Table III. Nonlinear models between tree biomass amounts or leaf area ( $Y$ : in $\mathrm{kg}$ or $\mathrm{m}^{2}$ ) and $\mathrm{dbh}$ (in $\mathrm{cm}$ ) and tree height (h: in $\mathrm{m}$ ).

\begin{tabular}{lccccccc}
\hline \multicolumn{1}{c}{$Y$} & $c l$ & $S E c I$ & $c 2$ & $S E c 2$ & $c 3$ & $S E c 3$ & $\mathrm{R}^{2}$ \\
\hline Leaves & 0.0167 & 0.0097 & 2.951 & 0.283 & -1.101 & 0.375 & 0.923 \\
Branches & 0.0114 & 0.0117 & 3.682 & 0.373 & -1.031 & 0.568 & 0.920 \\
Crown & 0.0183 & 0.0164 & 3.614 & 0.339 & -1.078 & 0.507 & 0.929 \\
Stem & 0.0109 & 0.0028 & 1.951 & 0.060 & 1.262 & 0.117 & 0.996 \\
Total & 0.0306 & 0.0119 & 2.347 & 0.096 & 0.590 & 0.183 & 0.991 \\
Leaf area & 0.2410 & 0.1230 & 2.899 & 0.240 & -0.984 & 0.322 & 0.942 \\
\hline
\end{tabular}

The models are of the form $\mathrm{Y}=\mathrm{c}_{1} * \mathrm{dbh}^{\mathrm{c} 2 *} \mathrm{~h}^{\mathrm{c} 3}$. Standard errors (SE) of the estimates are indicated. The number of observations is 38 . 
that dbh was proportional to the 0.50 power of the product of tree height and crown silhouette area.

$$
\begin{gathered}
\ln \left(\mathrm{h}^{*} \mathrm{c}_{s a}\right)=-10.433+1.813^{*} \ln (\mathrm{dbh}) \\
R^{2}=0.899
\end{gathered}
$$

Transformed to a power function it reads as follows:

$$
\mathrm{h}^{*} \mathrm{c}_{s a}=0.649 * \mathrm{dbh}^{1.81 .3}
$$

where $c_{s a}=$ crown silhouette area $\left(\mathrm{m}^{2}\right)$.

Tree leaf area and crown biomass were both correlated with crown projection area (fig 2). The relationships were best described by nonlinear regression equations:

$$
\begin{aligned}
\mathrm{la} & =3.38 * \mathrm{c}_{p u a}{ }^{1.028} \quad R^{2}=0.835 \\
\mathrm{w}_{c h} & =0.699 * \mathrm{c}_{p l a}^{1.351} \quad R^{2}=0.919
\end{aligned}
$$

where la $=$ tree leaf area $\left(\mathrm{m}^{2}\right) ; c_{p a}=$ crown projection area $\left(\mathrm{m}^{2}\right)$; and $\mathrm{w}_{c b}=$ crown biomass (kg).

\section{Biomass distribution}

The biomass amounts of the tree components were expressed as fractions of the total aboveground tree biomass. One tree had many stem forks; because the boundary between 'stem' and 'branch' was difficult to define, this tree was excluded from the calculation of the distribution curves. In general, the fraction stem biomass increased with increasing tree size, whereas the fraction leaf biomass decreased.

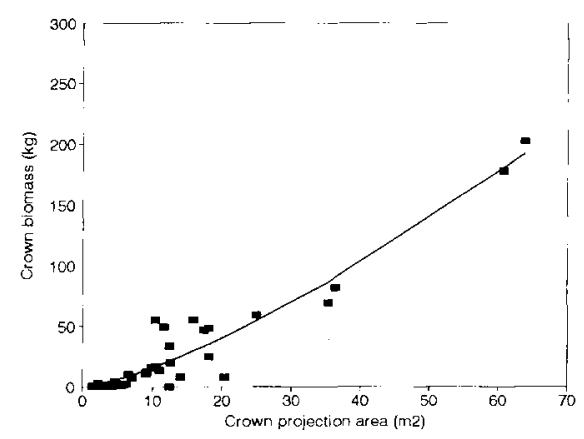

Fig 2. Relationships between crown projection area and crown biomass.
However, the regression constants differed significantly between trees from different diameter classes. Figure 3 presents the relative biomass distributions for each diameter class separately. Larger trees in a stand appeared to have relatively more crown biomass than smaller trees.

The amount of leaf biomass decreased with increasing branch biomass; no significant difference between diameter classes occurred. The ratio between leaf biomass and branch biomass (L/B ratio) decreased with increasing tree size. The most significant relationships appeared

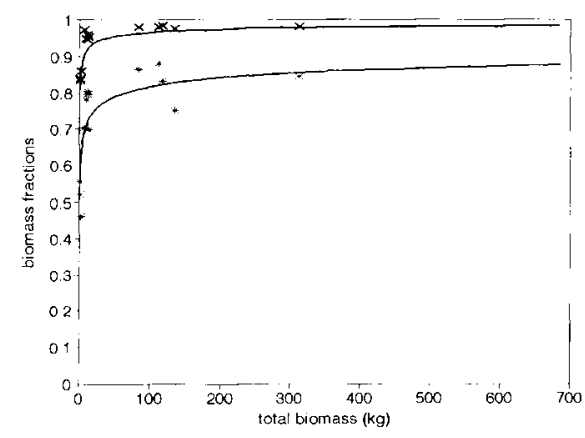

$\mathbf{a}$

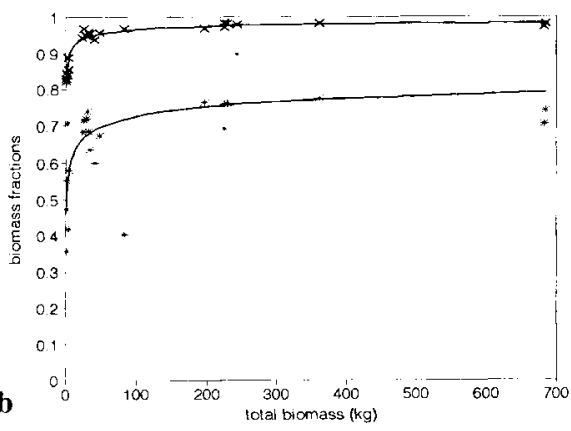

Fig 3. Relative aboveground biomass distribution. The symbols represent the fractions of stem biomass (asterisks) and stem-plus-branch biomass (crosses) of individual trees. The solid lines indicate how, according to the regression analysis, the relative amount of biomass is distributed over, respectively, the stem (lower part) and leaves (upper part) in the trees. Results are presented for a) suppressed trees and b) dominant trees. 


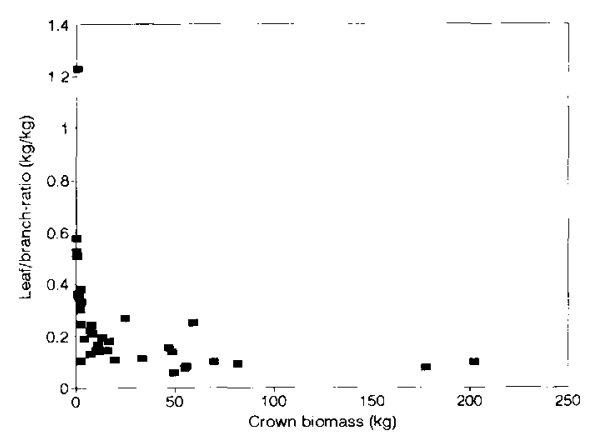

Fig 4. Leaf biomass/branch biomass ratio as a function of crown biomass.

when the $L / B$ ratio was related to $d b h$, tree height or crown biomass (fig 4).

\section{Specific leaf area}

Strong variation in SLA was found. SLA of leaf samples varied between 80 and $340 \mathrm{~cm}^{2} \mathrm{~g}^{-1}$, but overall SLA was remarkably consistent among the trees (weighted average SLA was $172 \mathrm{~cm}^{2} \mathrm{~g}^{-1}$, with a standard deviation of $16 \mathrm{~cm}^{2} \mathrm{~g}^{-1}$ ). Figure 5 presents the pattern of change of average SLA within the crown, derived from data of the 1993 sample trees. In the tree top SLA was 80 $120 \mathrm{~cm}^{2} \mathrm{~g}^{-1}$, increasing to $300-340 \mathrm{~cm}^{2} \mathrm{~g}^{-1}$ at the crown base. The pattern was consistent among the stands, though in the youngest stand height-related differences were less pronounced. To investigate the role of canopy closure, SLA measurements were also carried out on a small solitary tree (height $=2 \mathrm{~m}$ ). In this tree SLA showed the same trend, but differences were less pronounced than in the forest-grown trees: SLA decreased from on average of $180 \mathrm{~cm}^{2} \mathrm{~g}^{-1}$ at the crown base to $100 \mathrm{~cm}^{2} \mathrm{~g}^{-1}$ at the tree top.

\section{Sapwood-leaf area relationships}

None of the chemical indicators applied indicated any presence of heartwood; thus, hence sapwood area was considered to be equal to basal area (without bark) in all sample trees. Tree leaf area appeared to be strongly correlated with this sapwood area $\left(\mathrm{sa}_{h}\right)$. Ignoring the nonsignificant intercept resulted in a leaf area-sapwood

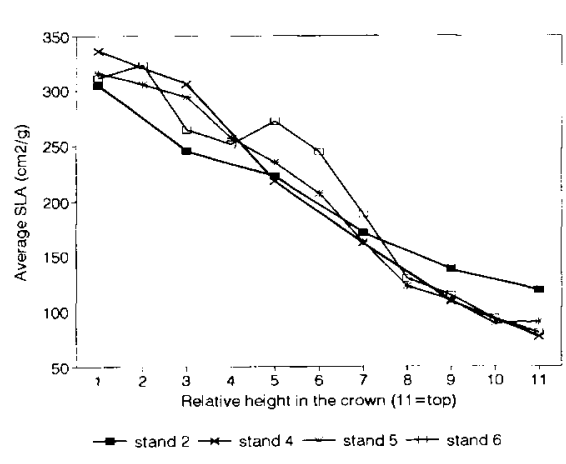

Fig 5. Mean specific leaf area (SLA) at different heights within the tree crowns. Heights are expressed as positions relative to the length of the living crown. Each SLA value was based on six samples, except for stand 6 where only two samples per height position were available.

area ratio of $0.331 \mathrm{~m}^{2} \mathrm{~cm}^{-2}\left(R^{2}=0.926\right)$; however, the relationship differed significantly between stands. Stand differences disappeared when crown dimensions, especially the height of the crown base, were used as covariables. Crown length data were available for the subsample (20 trees). In this subsample $\mathrm{sa}_{b / h}$ explained $96.2 \%$ of the variance in leaf area. This percentage was increased to 98.2 when the height of the crown base was applied as a co-variable. Equation [6] implies that in case of identical $\mathrm{sa}_{b / 1}$ amounts, trees having the lowest crown base will have the highest amount of leaf area.

$$
\mathrm{la}=0.341^{*} \mathrm{sa}_{j, h}-1.674 * \mathrm{~h}_{c h}, \quad R^{2}=0.982
$$

where $\mathrm{la}=$ tree leaf area $\left(\mathrm{m}^{2}\right) ; \mathrm{s} \mathrm{a}_{h i}=$ tree sapwood area at breast height $\left(\mathrm{cm}^{2}\right)$; and $\mathbf{h}_{c b}=$ height of the crown base $(\mathrm{m})$.

Total leaf area also appeared to be correlated with the area of the most recent growth rings. Best correlation was with the cross-sectional area of the three youngest rings $\left(R^{2}=83.6 \%\right)$.

\section{Stand biomass and leaf area index}

Stand biomass and LAI (table IV) were derived by applying the equations from table II. In figure 6 some stand totals are compared with data from the literature, as collected by Cannell 
(1982): all data on beech are included here, covering different sites and management regimes. Present data showed an almost linear increase of the total aboveground stand biomass with stand age (fig 6a). LAI in the closed-canopy stands generally varied between 5.5 and 7.2 (fig 6b): the low value of stand 2 can be ascribed to the large contribution to the canopy of the birches.

\section{DISCUSSION AND CONCLUSION}

\section{Allometric relationships}

The amounts of biomass presently found are comparable with data from Burger (1950) and Pellinen (1986). Dbh explained a large part of the variation in tree biomass, in accordance with results of others (Burger, 1950; Kakubari, 1983; Pellinen, 1986). The relationship between $\mathrm{dbh}$ and stem biomass was stand-independent, which can be expected as both are cumulative parameters. The relationship between $\mathrm{dbh}$ and leaf and branch biomass, in contrast, can be expected to differ between stands, as stand density will affect crown form and size (Burger, 1950). Adding parameters accounting for stand structure will reduce such variability, as was presently indicated by the increased $R^{2}$ when tree height was added to the allometric relationships. In the present data set, however, though some stand effects were visible, the relationships between $\mathrm{dbh}$ and foliage, respectively, branch biomass did not significantly differ between stands. The presently established models fitted well. However, because the leaf and branch biomass of the two largest trees had a relatively strong effect on the parameter estimations, care should be taken when the models are used for extrapolation.

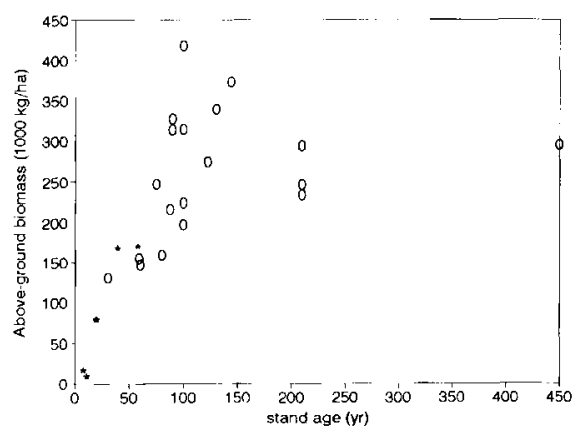

$\mathbf{a}$

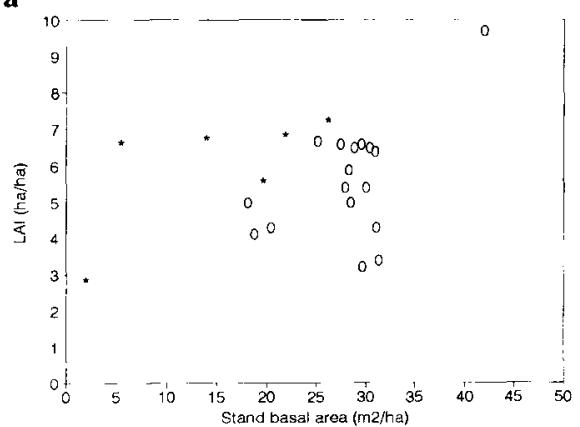

b

Fig 6. Stand data from present research (asterisks) and from the literature (circles), after Cannell (1982). a) Stand age versus aboveground biomass; b) stand basal area versus leaf area index (LAI).

The well-known relationship between $\mathrm{dbh}$ and tree height was confirmed by the present data set (eq [1]). This relationship can be regarded indicative for the mechanical support function of the stem. According to Niklas (1992), $\mathrm{dbh}$ is expected to be proportional to the $1.5-2.0$

Table IV. Biomass (ton.ha $\left.{ }^{-1}\right)$ and leaf area index (LAI) $\left(\mathrm{m}^{2} \cdot \mathrm{m}^{-2}\right)$ of the sample stands.

\begin{tabular}{ccccccc}
\hline Stand & Leaf & Branch & Stem & Total & LB ratio & LAI \\
\hline 1 & 3.01 & 0.64 & 9.96 & 13.61 & 4.70 & 6.58 \\
2 & 1.28 & 0.29 & 4.37 & 5.94 & 1.57 & 2.79 \\
3 & 3.61 & 8.45 & 63.10 & 75.16 & 0.43 & 6.71 \\
4 & 3.08 & 9.54 & 63.90 & 76.52 & 0.32 & 5.53 \\
5 & 4.22 & 33.38 & 126.90 & 164.5 & 0.13 & 7.18 \\
6 & 3.93 & 39.49 & 123.30 & 166.72 & 0.10 & 6.79 \\
\hline
\end{tabular}

L/B ratio: leaf biomass/branch biomass. 
power of tree height when primarily biomass (static loads) determines stem diameter. Inverting dependent and independent variables in equation [1] results in an exponent of 1.22 , which is clearly lower. An explanation for this might be that crown size is ignored. In the case where wind stress is most important, dbh will be proportional to the $0.33-0.50$ power of the product of crown silhouette area and the tree height, depending on the freedom of the base of the tree to move (Niklas, 1992): the presently found exponent of 0.50 supports this so-called constant stress model, implying that especially wind force will determine the relative increments in height and diameter.

\section{Biomass distribution}

The dry matter distribution pattern presented in figure 3 is comparable with the general pattern found in many tree species (see data Cannell, 1982). Presently, relatively large stand members had a higher fraction of leaf and branch biomass than smaller neighbors. Regarding diameter class as an indicator of dominance position, this means that dominance position affects the amount of crown biomass. Cannell (1989) concludes that in the case of increased inter-tree competition, a lower fraction of the dry matter will be allocated towards the branches, and probably towards the foliage as well. This coincides with the presently found effect of dominance position. Dominant trees therefore invest more in the canopy, and are thus able to maintain a relatively large crown. Including an indicator of a tree's dominance position would hence improve dry matter allocation keys.

Because foliage is concentrated at the end of the branches (the crown mantle) in order to optimize radiation interception (Kellomaki and Oker-Blom, 1981), relatively more branch biomass will be needed to physically support a unit leaf biomass when crown size increases. The decreasing $\mathrm{L} / \mathrm{B}$ ratio (fig 4 ) can thus be ascribed to crown expansion.

The ratio between leaf biomass and branch biomass was independent of diameter class. A certain amount of leaf biomass apparently needs a certain amount of supporting branch biomass, independent of a tree's dominance position, but dependent on its size.

\section{Specific leaf area}

SLA varied strongly, both in the vertical and in the horizontal plane (results not shown): values between 80 and $340 \mathrm{~cm}^{2} \mathrm{~g}^{-1}$ were found. SLA generally increased when going from the tree top downwards (fig 5). Comparable results have been reported by Decei (1983), Pellinen (1986) and Gratani et al (1987) in Fagus sylvatica, and by Tadaki (1970) in Fagus crenata. The variation in SLA is due to morphological differences between sun and shade leaves (Gratani et al, 1987), caused by differences in light conditions within the canopy (Kellomaki and Oker-Blom, 1981; Gratani et al, 1987). The presently found trend of SLA increasing towards the crown base can hence be explained by the decrease in radiation availability. This is supported by the fact that the rate of SLA increase was lower in the youngest stand and far lowest in the solitary tree: the light extinction rates here will be less pronounced due to, respectively, the relative open canopy (compare the basal areas in table I) and the absence of neighboring trees. Thus, stand density affects the rate of change of SLA with depth in the canopy.

Part of the variability in SLA might also be attributed to seasonal effects, as data collection was spread over 3 years. However, despite the large variation in SLA, overall SLA at the tree level was consistent among the trees. Tree leaf biomass and tree leaf area were strongly interrelated $\left(R^{2}=0.987\right.$ ), implying that at the tree level SLA is rather independent of stand density.

\section{Sapwood-leaf area relationships}

Presently, sapwood area explained $92.6 \%$ of the variance in leaf area (la). However, sapwood area $\left(\mathrm{sa}_{h h_{1}}\right)$ equaled basal area (without bark); no heartwood was found, which agrees with remarks from Hillis (1987) that in beech, heartwood is generally formed only after 80-100 years. Thus, the $\mathrm{l} / \mathrm{s} / \mathrm{s}_{h}$, ratio may as well point to the mechanical as to the functional support function of the stem. The significant role of the height of the crown base in the relationship between sah and la (eq [6]) is in agreement with 
the pipe model theory (Shinozaki et al, 1964): when leaf area is related to total cross-sectional stem area (ba), the la/ba ratio will decrease when going downward from the crown base to breast height, because transpiring tissue is lacking here. The length of the branch-free bole thus affects the $\mathrm{l} / \mathrm{s} / \mathrm{sa}_{b h}$ ratio, as is predicted by equation [6]: the higher the crown base, the lower the leaf area per unit sapwood area measured at breast height. It also implies that the water conductivity below the crown is not constant within the cross-sectional stem area. This can be explained by the fact that water conductivity decreases with ring aging, in conifers, in ring-porous, as well as in diffuse-porous species like beech (Zimmermann, 1983; Bamber and Fukazawa, 1985). However, due to the smaller vessels in diffuse-porous species when compared with ring-porous species, more growth rings can be expected to contribute to the vertical water transport in beech than, for example, only the recent one to three rings as in oak (Rogers and Hinckley, 1979).

Since in this study no water transport was measured, the estimation of the number of contributing rings was based on the regression analysis. The area of the three most recent growth rings gave the best result statistically, but explained clearly less of the variation in leaf area than did total sapwood area. Another reason for the correlation between leaf area and area of the recent rings might be that this reflects a different mechanism, for example assimilate translocation. Nevertheless, regarding the aging of growth rings, tree leaf area can be expected to be closer related to the area of a restricted number of growth rings than to the total basal area. Additional research on the contribution of separate growth rings to vertical water transport is necessary to determine whether a restricted number of (sapwood) growth rings contribute to the water transport, as has been found in some ring-porous species (Rogers and Hinckley, 1979).

\section{Maximum LAI and natural thinning}

The presently found biomass amounts are rather low, which is apparently due to the relative young age of the sample stands (fig 6a). Biomass is hence expected to further increase with stand age. LAI, in contrast, can be expected to reach a site-dependent maximum value (fig 6b). According to the data in figure $6 \mathrm{~b}$, it seems that for the present site type a maximum LAI of seven is reasonable, which is reached as soon as canopy-closure is complete. Note the large variability in LAI values in the literature data (Cannell, 1982), which is probably due to site differences.

LAI depends on the tree number and the amount of leaf area per tree, and is not expected to exceed $\mathrm{LAI}_{\text {max }}$ (Jarvis and Leverenz, 1983; Landsberg, 1986). Thus, the following relationship appears:

$$
\mathrm{LAI}_{\operatorname{mat}}=\mathrm{N}_{\max } * 1 \mathrm{a}_{a x} / 10000
$$

where $\mathrm{LAI}_{\text {max }}=$ site-specific maximum LAI (ha $\left.\mathrm{ha}^{-1}\right) ; \mathrm{N}_{\text {max }}=$ maximum number of living trees $\left(\mathrm{ha}^{-1}\right)$; and $\mathrm{la}_{t}=$ average tree leaf area $\left(\mathrm{m}^{-2}\right)$.

Referring to the presently found linear relationship between leaf area and basal area, equation [7] can also be described as:

$$
\mathrm{LAI}_{m k L 1}=\mathrm{N}_{m u t} * \mathrm{r}^{*}(\pi / 4)^{*} \mathrm{dbh}^{2} / 10000
$$

where $r$ is equal to $0.331 \mathrm{~m}^{2}$ leaf per $\mathrm{cm}^{2}$ basal area.

Assuming a maximum LAI implies that selfthinning among the stand members will occur (see Harper, 1977; Landsberg, 1986). The actual tree number $(\mathrm{N})$ is thus dependent on the maximum LAI that can be maintained. Replacing $\mathrm{N}_{\text {mar }}$ by $\mathrm{N}$ and rewriting equation [8] results in:

$$
\mathrm{dbh}=\mathrm{k} * \mathrm{~N}^{-0.5}
$$

where $\mathrm{k}=\left(40000 * \mathrm{LAI}_{\text {max }} /\left(\pi^{*} \mathrm{r}\right)\right)^{0.5}$.

When expressed in terms of stem biomass (see table II) this becomes:

$$
\mathrm{W}_{1}=\mathrm{k}_{2} * \mathrm{~N}^{-1.262}
$$

where $\mathrm{k}_{2}=0.0762 * \mathrm{k}^{2.523}$.

The power represents the slope of the selfthinning line. The value -1.262 is a little lower than the generally expected -1.5 (Harper, 1977; White, 1981), which probably is due to the fact that stem biomass instead of total plant weight was used. Another reason might be that in the case of increasing competition, some trees initially show decreasing leaf amounts, so maxi- 
mum LAI will be reached just before the onset of self-thinning.

Equation [9] states that as the trees grow (the average diameter increases), the number of trees will decline: the amount of biomass that can be maintained on a certain site depends on the site-specific maximum LAI. This dependency makes LAI a causal factor when simulating natural mortality in forest stands. A comparable theoretical analysis of the role of maximum LAI was carried out by Landsberg (1986).

Applying equation [9] with the current parameter values also implies that stand basal area remains constant as long as LAI is at its maximum value. From $\mathrm{G}=\mathrm{N}^{*}(\pi / 40000)^{*} \mathrm{dbh}^{2}$ and equation [9] it follows that:

$$
\begin{aligned}
\mathrm{G} & =\left(40000 * \mathrm{LAI}_{\text {mux }} /\left(\pi^{*} \mathrm{r}\right)\right)^{*} \mathrm{dbh}^{-2} \\
& *(\pi / 40000)^{*} \mathrm{dbh}^{2}=\mathrm{LAI}_{\text {mat }} / \mathrm{r}
\end{aligned}
$$

Based on the present data and assuming $\mathrm{LAI}_{\text {max }}=7, \mathrm{G}$ is estimated at $21 \mathrm{~m}^{2} /$ ha from equation [11].

Note, however, that although presently no heartwood was detected, leaf area can be expected to be proportional to the water-transporting cross-sectional area rather than to the basal area (Shinozaki et al, 1964; Cannell, 1989). As a result, the term $\mathrm{dbh}^{-2}$ in equation [11] should actually be (water-transporting-area) ${ }^{-1}$. Because this area is generally lower than the tree's basal area, $\mathrm{G}$ can be expected to gradually increase with average tree diameter, ie, with stand age.

\section{ACKNOWLEDGMENTS}

This research was carried out as part of the EGENVIRONMENT II programme (contract no EV5V-CT94-0468/LTEEF). The author wishes to thank J Goudriaan, GMJ Mohren, AFM van Hees, the PhD students from the Department of Theoretical Production-Ecology and two anonymous reviewers for their useful comments on earlier drafts.

\section{REFERENCES}

Bamber RK, Fukazawa K (1985) Sapwood and heartwood. A review. For Abstr 46, 567-580
Burger H (1950) Holz Blattmenge und Zuwachs X: die buche. Mitt Schweiz Anst Forst Versuchsw 26, 419-468

Cannell MGR (1982) World Forest Biomass and Primary Production Data. Academic Press, New York, NY, USA, $391 \mathrm{p}$

Cannell MGR (1989) Physiological basis of wood production: a review. Scand J For Res 4, 459-490

Causton DR (1985) Biometrical, structural and physiological relationships among tree parts. In: Attributes of Trees as Crop Plants (MGR Cannell, JE Jackson, eds), Inst Terrestrial Ecology, Huntingdon, UK, 137-159

Decei I (1983) Étude de la phytomasse du feuillage dans les peuplements de Fagus sylvatica L. In: Mesures des biomasses et des accroissements forestiers (D Auclair, ed), Proceedings, IUFRO S4.01.00 Meeting, Orléans, France

Gratani L, Fida C, Fiorentino E (1987) Ecophysiological features in leaves of a beech ecosystem during the growing period. Bull Soc R Bot Belg 120,81-88

Harper JL (1977) Population Biology of Plants. Academic Press, London, UK, 174-189

Hillis WE (1987) Heartwood and Tree Exudates. Springer series in wood science, Springer-Verlag, Berlin, Germany

Jarvis PG, Leverenz JW (1983) Productivity of temperate, deciduous and evergreen forests. In: $P h y-$ siological Plant Ecology. IV. Encyclopedia of Plant Physiology, New Series, Vol 2D (OL Lange, PS Nobel, CB Osmond, H Ziegler, eds), SpringerVerlag, New York, NY, USA, 233-280

Kakubari Y (1983) Vergleiche Untersuchung über die Biomasse-unterschied awischen europäischen und japanischen Buchenwald. Bull Tokyo Univ For 33, Faculty of Agriculture, University of Shizuoka, Japan

Kellomaki S, Oker-Blom P (1981) Specific needle area of Scots pine and its dependence on light conditions inside the canopy. Silva Ferm 15, 190-198

Kraft G (1884) Beitraege zur Lehre von den Durchforstungen. Schlagstellungen und Lichtungstrieben. Klindworth, Hannover, Germany, $147 \mathrm{p}$

Landsberg JJ (1986) Physiological Ecology of Forest Production. Academic Press, New York, NY, USA

Niklas KJ (1992) Plant Biomechanics: an Engineering Approach to Plant Form and Function. The Univ of Chicago Press Lid, London, UK, 410-415

Pellinen P (1986) Biomasseuntersuchungen im Kalkbuchenwald. Dissertation, Universität Göttingen, Germany, $134 \mathrm{p}$ 
Rogers R, Hinckley TM (1979) Foliar weight and area related to current sapwood area in oak. For Sci 25 , 298-303

Shinozaki K, Yoda K, Hozumi K, Kira T (1964) A quantitative analysis of plant form. The pipe model theory II. Further evidence of the theory and its application in forest ecology. Jpn Ecol 14, 133-139
Tadaki Y (1970) Studies on the production structure of forest. XVII. Vertical change of specific leaf area in forest canopy. $J J p n$ For Soc $52,263-268$

White J (1981) The allometric interpretation of the self-thinning rule. $J$ Theor Biol $89,475-500$

Zimmermann MH (1983) Xylem Structure and the Ascent of Sap. Springer-Verlag, Berlin, Germany, $139 \mathrm{p}$ 